\title{
Serological survey on Leptospirosis of cattle in Cu Chi, Ho Chi Minh City
}

\author{
Mai C. Duong ${ }^{1 *}$, Toan T. Nguyen $^{1}$, Thong H. Phan ${ }^{1}$, \& Phuong P. B. Nguyen ${ }^{2}$ \\ ${ }^{1}$ Faculty of Animal Science and Veterinary Medicine, Nong Lam University, Ho Chi Minh City, Vietnam \\ ${ }^{2}$ Division of Sub-department of Animal Health Ho Chi Minh City, Vietnam
}

ARTICLE INFO
Research Paper
Received: March 30, 2020
Revised: May 15, 2020
Accepted: June 19, 2020
Keywords
Cattle
Leptospira
MAT
Prevalence
Serovar
*Corresponding author
Duong Chi Mai
Email: mai.duongchi@hcmuaf.edu.vn

\section{ABSTRACT}

Leptospirosis is a zoonotic disease of global importance, especially in tropical countries. The purpose of this study to evaluate the seroprevalence of Leptospira in cattle in Ho Chi Minh city. Serum samples from 446 animals were tested by microscopic agglutination test (MAT) using a panel of 24 Leptospira serovars kits provided by Ho Chi Minh City Pasteur Institute. Results showed that seroprevalence of Leptospira at herd-level was $61.54 \%$; and at individual-level was $31.17 \%$. In which, the percentage of beef cattle $(29.77 \%)$ infected with Leptospira was lower than that of dairy cattle $(31.75 \%)$. Cattle from 2 to 3 years of age had the highest rate of Leptospira infection in was $37.72 \%$. According to herd size, the results found that medium-scale farming (from 25 to 50 animals) had the lowest seroprevalence rate with Leptospira spp. $(28.65 \%)$. No significant differences were found among aged groups of cattle. There were a totally 7 serovars that were detected in cattle, in which, the two most popular serovars were L. Hardjo bovis $(31.37 \%)$ and L. Hebdomadis (30.26\%). There were twelve animals infected with four Leptospira serovars (8.63\%); meanwhile, the majority of animals infected with one serovar were $42.45 \%$. The ratio of positive animals at antibody titer of 1:200 was $53.70 \%$. These results indicated a very high exposure of $\mathrm{Cu}$ Chi cattle to Leptospira spp. which consequently posed a definite risk for people working with cattle acquiring this zoonotic infection.

Cited as: Duong, M. C., Nguyen, T. T., Phan, T. H., \& Nguyen, P. P. B. (2020). Serological survey on Leptospirosis of cattle in $\mathrm{Cu}$ Chi, Ho Chi Minh City. The Journal of Agriculture and Development 19(3), 52-56.

\section{Introduction}

Leptospirosis is a neglected zoonotic disease and can be devastating to both human and animal health globally. It is caused by pathogenic bacteria of the Leptospira genus from the family Leptospiraceae (Levett, 2001). This disease is mostly endemic in humid tropical or subtropical countries. Animals or humans can be infected with this pathogen from exposure to contaminated reservoirs such as carrier mammals, contamination of soil and water. Domestic animals act as a reservoir for pathogenic Leptospira represents a significant health risk to a wide range of workers, veterinarians and slaughterhouse work- ers (Adler \& Adela, 2010). It was estimated that seven to ten million people were infected by leptospirosis per year and almost 58,900 deaths occurred per year (Costa et al., 2015). Leptospira was first identified in 1930 and is known to be endemic for leptospirosis with a peak during the rainy season (Laras et al., 2002). In dairy cattle, though Leptospirosis is sub-clinical or mild in most cases, severe illness can sometimes end fatally, a series of clinical signs such as abortion, mastitis, loss of milk are found. According to WHO (2011), "there is little research on the economic impact of leptospirosis, and information is lacking about the societal costs of the disease, including the costs of health care, lost productivity 
Table 1. The seroprevalence of Leptospira at herd-level by region

\begin{tabular}{lccc}
\hline Regions & $\begin{array}{c}\text { Number of } \\
\text { households }\end{array}$ & $\begin{array}{c}\text { Number of households } \\
\text { contained positive cattle }\end{array}$ & Ratio (\%) \\
\hline An Nhon Tay & 7 & 2 & 28.57 \\
An Phu & 10 & 7 & 70.00 \\
Binh My & 3 & 2 & 66.67 \\
Hoa Phu & 5 & 0 & 0.00 \\
Nhuan Duc & 3 & 3 & 100.00 \\
Pham Van Coi & 1 & 1 & 100.00 \\
Phu Hoa Đong & 6 & 2 & 33.33 \\
Phu My Hung & 5 & 2 & 40.00 \\
Phuoc Hiep & 2 & 1 & 50.00 \\
Phuoc Thanh & 5 & 5 & 100.00 \\
Phuoc Vinh An & 4 & 0 & 0.00 \\
Tan Thanh Dong & 23 & 17 & 73.91 \\
Tan Thanh Tay & 4 & 2 & 50.00 \\
Thai My & 2 & 2 & 100.00 \\
Trung An & 5 & 5 & 100.00 \\
Trung Lap Ha & 2 & 2 & 100.00 \\
Trung Lap Thuong & 4 & 3 & 75.00 \\
\hline Total & 91 & 56 & 61.54 \\
\hline
\end{tabular}

caused by sequelae, and death of livestock". However, it showed a significant public health problem and the economic losses result from infertility, abortion, poor milk yield (Lloyd-Smith et al., 2007). The aim of this study to assess the seroprevalence of Leptospira in cattle in Ho Chi Minh City. This information will be reference documents to determine the strategy of leptospirosis prevention and control in humans and animals in Ho Chi Minh City.

\section{Materials and Methods}

Serum samples from 446 cattle were collected from 90 households in $\mathrm{Cu}$ Chi district, Ho Chi Minh city from July to October, 2020. Information about the cattle including breed, age, gender, day of vaccination and day of sample collection were recorded. There are about $30-40 \%$ cattle of total number of cattle per household chosen randomly to collect blood sample. Then, blood samples were left to clot naturally at room temperature. Sera from those tubes after blood clotting were centrifuged to be completely clear and free of hemolyzed blood cells. All sera were labeled with the animal identification number before being stored at $-70^{\circ} \mathrm{C}$ until testing using MAT. Total of twenty four serovars were chosen based on the test kit provided by the Pasteur Institute, Ho Chi Minh City. Each tube of Leptospira contained approximately $2 \times 10^{8}$ leptospires $/ \mathrm{mL}$. The principle of the MAT reaction is the agglutination reaction occurred between the surface of live Leptospira and the specific antibody in the test serum against Leptospira. The degree of agglutination of the antigen-antibody complex was assessed under a dark-field microscope. This test detects antibodies specific for the Leptospira bacteria and is the World Health Organization gold standard test to diagnose leptospirosis.

For data analysis, the overall seroprevalence, prevalence of each serovar, and 95\% confidence intervals were calculated by utilizing Excel 2016 . Chi-square tests were used to compare the differences in the proportion of seroprevalence of each serovar according to herd size, age group and other variables according to the Minitab 16.0 software.

\section{Results and Discussion}

According to Table 1 the result showed that the highest percentage of households with cattle infected with Leptospira spp. was 100\% in Nhuan Duc, Pham Van Coi, Phuoc Thanh, Thai My, Trung An and Trung Lap Ha. The statistical difference was found in the proportion of households with infected animals among regions $(P<0.05)$. Previously using an agglutination test with the 
Table 2. The seroprevalence of Leptospira spp. in cattle

\begin{tabular}{|c|c|c|c|c|}
\hline & & $\begin{array}{c}\text { Number of tested } \\
\text { samples }\end{array}$ & $\begin{array}{c}\text { Seropositive } \\
\text { samples (a titer } \geq \\
1 / 100 \text { for any } \\
\text { serovars) }\end{array}$ & Ratio (\%) \\
\hline \multirow{17}{*}{ Regions } & An Nhon Tay & 32 & 4 & 12.50 \\
\hline & An Phu & 70 & 25 & 35.71 \\
\hline & Binh My & 11 & 3 & 27.27 \\
\hline & Hoa Phu & 23 & 0 & 0.00 \\
\hline & Nhuan Duc & 14 & 7 & 50.00 \\
\hline & Pham Van Coi & 3 & 2 & 66.67 \\
\hline & Phu Hoa Đong & 28 & 3 & 10.71 \\
\hline & Phu My Hung & 18 & 4 & 22.22 \\
\hline & Phuoc Hiep & 10 & 2 & 20.00 \\
\hline & Phuoc Thanh & 26 & 12 & 46.15 \\
\hline & Phuoc Vinh An & 14 & 0 & 0.00 \\
\hline & Tan Thanh Dong & 117 & 48 & 41.03 \\
\hline & Tan Thanh Tay & 19 & 6 & 31.58 \\
\hline & Thai My & 8 & 5 & 62.50 \\
\hline & Trung An & 25 & 5 & 20.00 \\
\hline & Trung Lap Ha & 9 & 4 & 44.44 \\
\hline & Trung Lap Thuong & 19 & 9 & 47.37 \\
\hline \multirow{3}{*}{$\begin{array}{l}\text { Herd size } \\
\text { (heads) }\end{array}$} & $<25$ & 218 & 68 & 31.19 \\
\hline & $\geq 25-<50$ & 171 & 49 & 28.65 \\
\hline & $\geq 50$ & 57 & 22 & 38.60 \\
\hline \multirow{2}{*}{$\begin{array}{l}\text { Types of } \\
\text { cattle } \\
\end{array}$} & Beef cattle & 131 & 39 & 29.77 \\
\hline & Dairy cattle & 315 & 100 & 31.75 \\
\hline \multirow{5}{*}{$\begin{array}{c}\text { Age } \\
\text { (years) }\end{array}$} & $<1$ & 34 & 11 & 32.35 \\
\hline & $\geq 1-\leq 2$ & 137 & 33 & 24.09 \\
\hline & $>2-\leq 3$ & 114 & 43 & 37.72 \\
\hline & $>3-\leq 4$ & 85 & 29 & 34.18 \\
\hline & $>4$ & 76 & 23 & 30.26 \\
\hline
\end{tabular}

same panel of Leptospira spp. strains provided by the Pasteur Institute, Ho Chi Minh City, this result was consistent with the results of Pham (2016), the rate of household with cattle infected with Leptospira was $61.22 \%$ in 6 districts $(\mathrm{Cu}$ Chi, Binh Chanh, Hoc Mon, Thu Duc, 9 and 12) of Ho Chi Minh City.

In Table 2, of 446 serum samples were tested by MAT method, there were 139 seropositive samples with a titer $\geq 1 / 100$ for any serovars were found, accounting for $31.17 \%$. No significant differences were found among groups with herd size and type of cattle $(P>0.05)$. Risk factors, including the use of well or stream water, minding livestock, walking barefoot, and the presence of rats and cats at home, were associated with being exposed to Leptospira (Ganoza et al., 2006). It is likely related to the increased risk of expo- sure, transmission and persistence of infections in larger intensive herds. Lilenbaum \& Santos (1996) reported that there was a positive association between herd size and the presence of cattle infected with serovar Hardjo. However, there was limited understanding regarding seroprevalence and transmission of pathogenic Leptospira in herds comprised of both dairy and beef cattle (Martins et al., 2011).

Moreover, in accordance with other studies, $L$. Hebdomadis $(30.26 \%)$ and $L$. Hardjo hardjo bovis $(31.37 \%)$ were also the most popular leptospires in cattle in Ho Chi Minh City (Table 3 ) and the ratios were $23.10 \%$ and $18.05 \%$, respectively (Tran, 2016). In Northern Ireland, Ellis and others made the remarkable observation that serovar hardjo was present in $41.6 \%$ of 245 randomly selected aborted bovine fetuses (Ellis et 
Table 3. Serovar distribution among 131 seropositive cattle determined by positive MAT (titer $\geq 1: 100$ )

\begin{tabular}{lcc}
\hline Serovars tested & Number of cases & Frequency (\%) \\
\hline L. Autumnalis & 6 & 2.21 \\
L. Bataviae & 3 & 1.10 \\
L. Hardjo Hardjo-bovis & 85 & 31.37 \\
L. Hardjo Hardjoprajitno & 51 & 18.82 \\
L. Hebdomadis & 82 & 30.26 \\
L. Tarassovi & 35 & 12.92 \\
L. Vughia & 9 & 3.32 \\
\hline
\end{tabular}

Table 4. The percentage of positive samples reacting with one or more serovars

\begin{tabular}{ccc}
\hline Number of positive serovars & Seropositive samples (a titer $\geq 1 / 100$ for any serovars) & Ratio (\%) \\
\hline 1 & 59 & 42.45 \\
2 & 40 & 28.78 \\
3 & 28 & 20.14 \\
4 & 12 & 8.63 \\
\hline Total & 139 & 100.00 \\
\hline
\end{tabular}

Table 5. Antibody titers rates are agglutinated to Leptospira

\begin{tabular}{cccccc}
\hline Antibody titer mean value & $1 / 100$ & $1 / 200$ & $1 / 400$ & $1 / 800$ & Total \\
\hline Number of MAT positive & 42 & 145 & 72 & 11 & 270 \\
$\%$ & 15.56 & 53.70 & 26.67 & 4.00 & 100.00 \\
\hline
\end{tabular}

al., 1982). According to Radostits et al., (2000) reported that serovar Hardjo is usually the mostprevalent in the cattle world widely and is considered the most adapted to cattle. This result was in agreement with the study of Bahlibi (2015), the prevalence was significantly highest in cattle with greater than 6 year's age group $(29.7 \%)$, followed by 3 to 6 years age group (23.2\%); while the lowest rate was found in cattle less than three years old $(6.7 \%)$. It was likely that the older animals were not at greater risk of infection by this organism, but this may be a reflection of the long duration and persistence of antibodies in the animals and a longer period of exposure.

Table 4 showed the majority $(42.45 \%)$ of the cattle which was tested positive for MAT results showed a reaction to only one serovar, and the rest reacted multiple serovars. The highest numbers of serovars detected were four serovars in 12 animals (8.63\%) (Table 4). According to Cousins et al. (1989), each serovar is adapted to a particular maintenance host, although they may cause disease in any mammalian species. Cattle are maintenance hosts for $L$. borgpetersenii serovar Hardjo. $\mathrm{Cu}$ Chi district was large and adjacent to many neighboring provinces such as Tay
Ninh, Binh Duong and Long An, this leads to the transportation and trade of cattle occurred more frequently and created favorable conditions for pathogens to spread and infect easily (Tran, 2016).

Antibody titers in this study ranged from 1:100 to 1:800. With 270 Leptospira-positive serum samples, there were $145(53.70 \%)$ positive cattle for agglutination test at $1 / 200$ dilution and 11 cattle showed samples with an antibody titer against serovar L. hardjo bovis and L. hebdomatic at of $1 / 800$ dilution (Table 5).

As mentioned above, samples are considered to be positive if agglutination occurred at a titer of $1 / 100$ or more (OIE, 2014). However, a titer of $\geq$ 100 is often used as evidence of past exposure (Faine \& WHO, 1982). According to the Centers for Disease Control and Prevention (CDCP, 1997), a titer of $\geq 200$ is used to define a probable case with a clinically compatible illness and this defining case occurred in a population in which exposure to leptospirosis is uncommon; but, a higher cut-off titer is necessary for defining probable cases of leptospirosis in most tropical countries. According to the guidelines of the Veterinary Department of Ho Chi Minh City, cattle 
infected with Leptospira spp. at antibody titer rates of $1 / 200$ or higher must be treated with antibiotics. All cases of positive cattle at 1/200 to $1 / 800$ titer should be isolated from their herds and treated with antibiotics. After this, the second serum samples would be collected at an interval of 10 to 14 days between samples (repeated sampling) to check if treatment was effective or infected cattle should be culled. In areas where leptospirosis is endemic, a single titer of $\geq 800$ in symptomatic patients is generally indicative of leptospirosis (Faine, 1988).

\section{Conclusions}

In conclusion, of 446 cattle serum samples assayed for anti-leptospiral antibodies by microscopic agglutination testing, $85(31.37 \%)$ reacted with serovar Hardjo hardjo bovis and $82(30.26 \%)$ with serovar Hebdomadis. Results obtained in this study raised our concerns about the spread of infection of leptospirosis in cattle in $\mathrm{Cu} \mathrm{Chi}$ district and will be used for the development of leptospirosis control program in $\mathrm{Cu}$ Chi district.

\section{References}

Adler, B., \& Adela, P. M. (2010). Leptospira and leptospirosis. Veterinary Microbiology 140, 287-296.

Bahlibi, W. S. (2015). Assessment of major reproductive problems of dairy cattle in selected sites of central zone of Tigrai region, Northern Ethopia (Unpublished master's thesis). Mekelle University, Mekelle, Ethiopia.

CDCP (Centers for Disease Control and Prevention). (1997). Case definitions for infectious conditions under public health surveillance. Morbidity and Mortality Weekly Report 46.

Costa, F., Hagan, J. E., Calcagno, J., Kane, M., Torgerson, P., Martinez-Silveira, M. S., Stein, C., AbelaRidder, B., \& Ko, A. I. (2015). Global morbidity and mortality of leptospirosis: A systematic review. PLOS Neglected Tropical Diseases 9(9).

Cousins, D. V., Ellis, T. M., Parkinson, J., \& McGlashen, C. H. (1989). Evidence for maintenance hosts for Leptospira interrogans serovar hardjo. Veterinary Record $124,872-874$.

Ellis, W. A., Olbrien, J. J., Neill, S. D., Ferguson, H. W., \& Hanna, J. (1982). Bovine leptospirosis: Microbiological and serological findings in aborted fetuses. Veterinary Record 110, 147-150.
Faine, S., \& WHO. (1982). Guidelines for the control of leptospirosis. Retrieved March 30, 2020, from https://apps.who.int/iris/handle/10665/37219.

Faine, S. (1988). Leptospirosis. in laboratory diagnosis of infectious diseases: Principles and practice. In Balows, A., Hausler, W. J., Ohashi M., \& Turano A. (Eds.). Bacterial Mycotic and Parasitic Diseases (344-352). New York, USA: Springer.

Laras, K., Cao, B. V., Bounlu, K., Nguyen, T. K., Olson, J. G., Thongchanh, S., Tran, N. V., Hoang, K. L., Punjabi, N., Ha, B. K., Ung, S .A., Insisiengmay, S., Watts, D. M., Beecham, H. J., \& Corwin, A. L. (2002). The importance of leptospirosis in Southeast Asia. The American Journal of Tropical Medicine and Hygiene 67, 278-286.

Levett, P.N . (2001). Leptospirosis. Clinical Microbiology Reviews 14(2), 296-326.

Lilenbaum, W., \& Santos, M. R. C. (1996). Effect of management systems on the prevalence of bovine leptospirosis. Veterinary Record 138, 570-571.

Lloyd-Smith, J. O., Greig, D. J., Hietala, S., Ghneim G. S., Palmer, L., Leger, J. S., Grenfell, B. T., \& Gulland, F. M. (2007). Cyclical changes in seroprevalence of leptospirosis in California sea lions. BMC Infectious Diseases 7, 125-136.

Martins, G., Penna, B., \& Lilenbaum, W. (2011). Differences between seroreactivity to leptospirosis in dairy and beef cattle from the same herd in Rio de Janeiro, Brazil. Tropical Animal Health and Production 44(3), 377-378.

Phan, G. T. H. (2016). The rate of Leptospira infection in dairy cows in Ho Chi Minh City (Unpublished bachelor's thesis). Nong Lam University, Ho Chi Minh City, Vietnam.

Radostits, O. M., Gay, C. C., Blood, D. C., \& Hinchcliff, K.W. (2000). Bovine mastitis: Veterinary medicine a textbook of the diseases of cattle, sheep, pigs, goats and horses ( $9^{\text {th }}$ ed.). London, UK: Saunders.

Tran, O. K. (2016). The rate of Leptospira infection in dairy cows in Hoc Mon and $\mathrm{Cu}$ Chi districts, Ho Chi Minh City (Unpublished bachelor's thesis). Nong Lam University, Ho Chi Minh City, Vietnam.

WHO (World Health Organization). (2011). Weekly epidemiological record (WER). Retrieved March 30, 2020, from https://www.who.int/wer/en/. 